\title{
Tau Aggregation Inhibitor Therapy: An Exploratory Phase 2 Study in Mild or Moderate Alzheimer's Disease
}

\author{
Claude M. Wischik ${ }^{\mathrm{a}, *}$, Roger T. Staff ${ }^{\mathrm{b}}$, Damon J. Wischik ${ }^{\mathrm{c}}$, Peter Bentham ${ }^{\mathrm{d}}$, Alison D. Murray ${ }^{\mathrm{e}}$, \\ John M.D. Storey ${ }^{\mathrm{f}}$, Karin A. Kook ${ }^{\mathrm{g}}$ and Charles R. Harrington ${ }^{\mathrm{a}}$ \\ ${ }^{a}$ School of Medicine and Dentistry, University of Aberdeen, Aberdeen, UK \\ ${ }^{\mathrm{b}}$ Aberdeen Royal Infirmary, NHS Grampian, Aberdeen, UK \\ ${ }^{\mathrm{c}}$ Computer Science Department, University College London, UK \\ ${ }^{\mathrm{d}}$ College of Medical and Dental Sciences, University of Birmingham, Birmingham, UK \\ ${ }^{\mathrm{e}}$ Aberdeen Biomedical Imaging Centre, School of Medicine and Dentistry, University of Aberdeen, Aberdeen, UK \\ ${ }^{\mathrm{f}}$ Department of Chemistry, University of Aberdeen, Aberdeen, UK \\ g Salamandra LLC, Bethesda, Maryland, USA
}

Accepted 17 December 2014

\begin{abstract}
.
Background: As tau aggregation pathology correlates with clinical dementia in Alzheimer's disease (AD), a tau aggregation inhibitor (TAI) could have therapeutic utility. Methylthioninium (MT) acts as a selective TAI in vitro and reduces tau pathology in transgenic mouse models.

Objective: To determine the minimum safe and effective dose of MT required to prevent disease progression on clinical and functional molecular imaging outcomes.

Methods: An exploratory double-blind, randomized, placebo-controlled, dose-finding trial of MT (69, 138, and $228 \mathrm{mg} / \mathrm{day})$ was conducted in $321 \mathrm{mild} /$ moderate AD subjects. The primary outcome was change on the Alzheimer's Disease Assessment Scale-cognitive subscale (ADAS-cog) at 24 weeks relative to baseline severity. Effect of treatment on regional cerebral blood flow decline was determined in a sub-study in 135 subjects. After 24 weeks, subjects were re-consented to enter sequential 6- and 12-month blinded extension phases. Registered with ClinicalTrials.gov (NCT00515333).

Results: At 24 weeks, there were significant treatment benefits in two independent populations at the $138 \mathrm{mg} /$ day dose: in moderate subjects on the ADAS-cog scale (treatment effect: -5.42 units, corrected $p=0.047$ ) and two other clinical scales; in mild subjects on the more sensitive regional cerebral blood flow measure (treatment effect: $1.97 \%$, corrected $p<0.001$ ). With continued treatment for 50 weeks, benefit was seen on the ADAS-cog scale in both mild and moderate subjects. The delivery of the highest dose was impaired due to dose-dependent dissolution and absorption limitations.
\end{abstract}

Conclusion: The minimum safe and effective daily MT dose is $138 \mathrm{mg}$ and suggests that further study of MT is warranted in AD.

Keywords: Alzheimer's disease, controlled clinical trial, intervention studies, methylthioninium, safety, tau protein

\footnotetext{
*Correspondence to: Claude M. Wischik, MD, PhD, TauRx Therapeutics Ltd., Liberty Building, Foresterhill Road,
}

Aberdeen AB25 2ZP, $\quad$ Scotland. Tel.: +441224 438550; Fax:+44 1224 555173; E-mail: cmw@taurx.com. 


\section{INTRODUCTION}

Neurofibrillary tangles discovered by Alois Alzheimer [1] are made up of paired helical filaments (PHFs), composed predominantly of a $12 \mathrm{kDa}$ repeat-domain fragment of the microtubule-associated protein tau [2-4]. Numerous studies have confirmed a quantitative link for the spread of neurofibrillary tangle pathology and the quantity of aggregated tau with both the extent of clinical dementia and functional molecular imaging deficits in Alzheimer's disease (AD) [5-8]. In light of the repeated failures of trials targeting the amyloid- $\beta$ pathway in mild or moderate $\mathrm{AD}$ [9], there is increasing interest in the possibility that a tau aggregation inhibitor (TAI) could have therapeutic utility in AD [9-11].

Methylthioninium (MT) is a diaminophenothiazine and, as the chloride salt of oxidized $\mathrm{MT}^{+}$(MTC, methylthioninium chloride, "methylene blue"), has a long history of safe use, both as an approved treatment for methemoglobinemia [12], and experimentally in urolithiasis and bipolar disorder among others [13-15]. MT inhibits tau aggregation in vitro and dissolves PHFs from AD brain tissue [16]. We have recently reported that the estimated steady state trough brain concentration of MT and its pharmacologically active desmethyl metabolites in the human brain at the $138 \mathrm{mg} /$ day dose is $0.18 \mu \mathrm{M}$ [17]. This is in the same range as the $\mathrm{IC}_{50}$ value for dissolution of PHFs $(0.16 \mu \mathrm{M})$ and the calculated intracellular $\mathrm{Ki}$ for TAI activity $(0.12 \mu \mathrm{M})$ (Harrington et al., unpublished results). We have also reported elsewhere that MT produces a monotonic ascending dose-response in the brain concentration range $0.13-1.38 \mu \mathrm{M}$ in tau transgenic mouse models (Melis et al., Behav. Pharmacol., in press).

We report the results of the first phase 2 clinical trial of a TAI in 321 subjects with mild/moderate AD. The trial was designed as an exploratory double-blind, randomized, placebo-controlled, 24 week dose-finding study of MT as monotherapy in AD (Fig. 1). Treatment could be extended in a blinded fashion in two sequential extension phases. In addition, a nested hexamethyl-propyl-amine-oxime single photon emission computed tomography (HMPAO-SPECT) sub-study was conducted in 135 of the participating subjects to explore whether treatment could prevent progression of molecular imaging deficits. This paper reports the primary and secondary outcomes at 24 weeks and a post hoc exploratory analysis at 50 weeks after the first extension of treatment. Although safety data are reported from the second extension phase, there were too few subjects remaining on treatment through to 102 weeks to permit meaningful comparison of treatment groups.

\section{METHODS}

\section{Subjects}

English-speaking subjects were enrolled at 17 centers (UK, 16; Singapore, 1) between 21 September 2004 and 21 December 2007. Subjects had a diagnosis of probable AD by DSM-IV and NINCDS-ADRDA criteria, a Mini-Mental State Examination (MMSE) score between 10 and 26 inclusive and a Clinical Dementia Rating (CDR) score of 1 or 2 at entry. To be included and retained in the trial, subjects were not to be currently treated with cholinesterase inhibitors or memantine. The full inclusion and exclusion criteria are provided in Supplementary Material S1 and S2, including competency requirements for consent to participate. Apolipoprotein E4 status was not determined as earlier work had shown that it does not impact on levels of aggregated tau in the AD brain [18].

\section{Trial design}

Subjects were randomized at baseline to placebo or one of three doses of MT $(69 \mathrm{mg}, 138 \mathrm{mg}$, and $228 \mathrm{mg} /$ day, administered as $30 \mathrm{mg}, 60 \mathrm{mg}$, and $100 \mathrm{mg}$ MTC capsules taken three times per day with food) using blocks of size 10 (two per dose level). A separate randomization schedule was used for sites able to undertake HMPAO-SPECT scans (limiting randomization after 31 January 2005 to placebo, $138 \mathrm{mg}$ /day, or $228 \mathrm{mg} /$ day). The dose range was based on a theoretical pharmacokinetic model developed from published human and rat data $[19,20]$, and recommended dosing [21]. Following completion of 24 weeks, subjects were re-consented to enter sequential 6-month and 12-month extension phases ("E1" and "E2") with dosing changes indicated in Fig. 1. Dosing frequency remained the same throughout. In order to maintain blinding to the subject and raters, capsules and treatment packs were identical. Each MTC dose or placebo was a single dark-blue hard gelatin capsule and safety raters were not permitted to be efficacy raters. Alzheimer's Disease Cooperative Study Clinical Global Impression of Change (ADCS-CGIC) was independently assessed by a third rater blinded to the findings of the other two raters. The study remained double-blind throughout 2 years. 


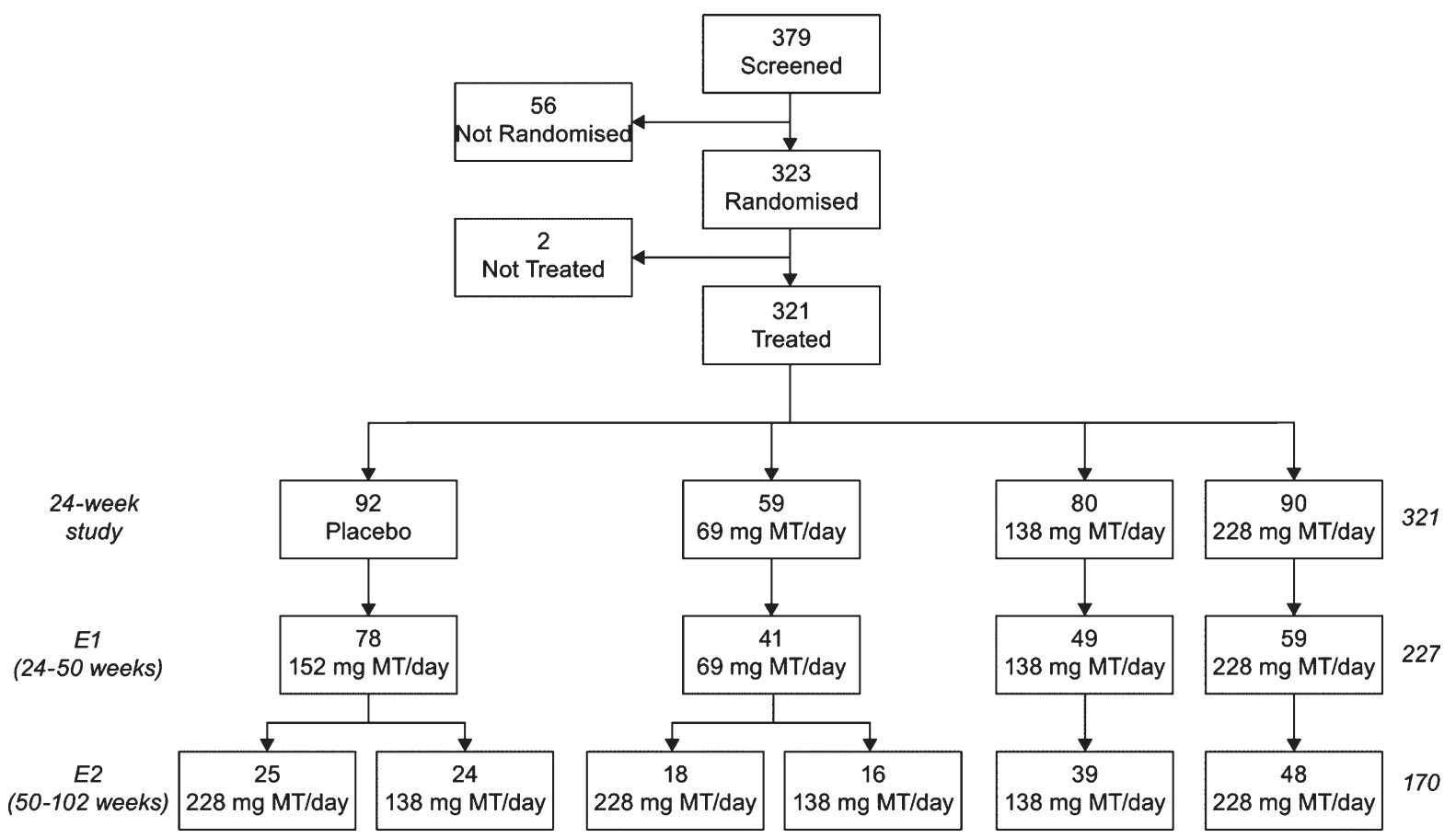

Fig. 1. Trial design.

The study was conducted in accordance with the Declaration of Helsinki and in compliance with the NHS Research Governance Framework, the International Conference on Harmonisation (ICH) Guidelines for Good Clinical Practice (GCP; CPMP/ICH/135/95, July 1996), and the European Directive on Clinical Trials (2004). The trial is registered at http://www. clinicaltrials.gov (NCT00515333).

\section{Clinical and imaging assessments}

The primary efficacy outcome was change in Alzheimer's Disease Assessment Scale-cognitive subscale (ADAS-cog) from baseline at 24 weeks. Secondary efficacy outcomes included ADCS-CGIC and change in MMSE score. Other secondary rating instruments and their assessment times are listed in Supplementary Material S3.

Change in regional cerebral blood flow (rCBF) was assessed by HMPAO-SPECT scan (see Supplementary Material S4) in all subjects enrolled at nine participating UK study sites with this capability. Baseline SPECT scans (or scans available within the previous 3 months) were performed before randomization. A follow-up scan was performed at the end of the initial 24 week study between 18 and 30 weeks after the first scan. The images were assessed by an expert neuroradiologist (ADM) and classified according to presence or absence of temporoparietal lobe reduction in $\mathrm{rCBF}$.

Subjects were monitored throughout for adverse events (AEs) and clinical laboratory testing was undertaken after 6, 12, and 24 weeks. Monitoring and laboratory testing continued during the extension phases.

\section{Statistical methods}

The statistical analysis plan was finalized 5 February 2007, and final data lock was on 20 February 2008. Since the study anticipated the theoretical possibility of non-response in moderate subjects due to more advanced pathology in medial temporal lobes [22], the statistical analysis plan specified that the primary analysis would assess the interaction between treatment and baseline severity as defined by baseline CDR (mild or moderate). The primary efficacy analysis of ADAS-cog change at 24 weeks was modelled as pre-specified using analysis of covariance, including covariates for treatment, baseline severity and a term for the interaction between treatment and severity. Additional terms for study center category (four levels), baseline ADAS-Cog score, age, gender, and previous exposure to acetylcholinesterase inhibitors or memantine were included. In the absence of prior 
dose-response information, Westfall's method, which does not require an a priori dose-response assumption, was pre-specified to correct for multiple comparisons [23]. This was applied separately for subjects with mild and moderate disease, and the resultant $p$ values were then further adjusted using the Bonferroni procedure (multiplied by 2 ), to provide correction for 6 treatment/severity levels, referred to in tables as "adjusted". The analysis was conducted using the modified intent-to-treat (mITT) population (ITT population who had at least one post-baseline, on-treatment efficacy assessment) with "last on-treatment observation carried forward" imputation for withdrawn subjects.

The clinical secondary outcome measures at 24 weeks were analyzed in the same way. ADCS-CGIC score was analyzed both as a dichotomous variable (declined versus same/improved) and also as a continuous variable. Analysis of MMSE was the same as for ADAS-cog. Mean change from baseline rCBF on HMPAO-SPECT was analyzed using region of interest (ROI) and statistical parametric mapping approaches [24]. For the ROI analysis, rCBF averaged across all brain regions was analyzed using linear modelling, with MT dose, a term for the interaction between treatment and severity, and temporoparietal lobe reduction pattern as fixed factors, and age and interval between scans as covariates. In addition, a statistical parametric mapping (SPM) approach was used to define the regions in which treatment response was seen without a priori brain mapping assumptions.

An exploratory analysis of ADAS-cog at 50 weeks was conducted using the same primary analysis model as for 24 weeks. Subjects randomized to placebo and then receiving a nominal dose of $152 \mathrm{mg} /$ day during weeks 24-50 served as the control arm for assessment of treatment effect at 50 weeks.

\section{Analysis of available dose}

The experimental procedures and results of stability/dissolution studies of the capsules used in the trial undertaken at the time the trial was initiated are reported in Baddeley et al. [17]. Likewise, the procedures and results of single-dose fed/fasting studies of MTC and a novel stable reduced form of MT $\left(\right.$ LMTX $\left.^{\circledR}\right)$, and a repeated-dose study of MTC, are reported in Baddeley et al. [17]. The calculation of total available dose and dose according to release within or after $60 \mathrm{~min}$ and the corresponding dose-response analyses of ADAS-cog effect size at 24 weeks and effect on reduction in red cell count have been reported previously [17].

\section{Role of the funding source}

The study was financed entirely by TauRx Therapeutics Ltd. TauRx took the lead in study design and study conduct.

\section{RESULTS}

\section{Subjects}

Subject disposition is summarized in Fig. 1. Of 321 subjects randomized, 294 were in the mITT population; of these 238, 176, and $62(81 \%, 60 \%$, and $21 \%$ ) remained on treatment at 24,50 , and 102 weeks, respectively. Baseline demographics and clinical characteristics are provided in Table 1. Overall, subjects were balanced with respect to severity of baseline disease based on MMSE. Of the 238 participants who completed the 24 week study, 135 (57\%) were imaged twice (after a mean of 20.3 weeks of treatment) and had images suitable for analysis.

\section{Primary analysis of ADAS-cog outcome at 24 weeks}

Table 2 reports change in ADAS-cog score and difference with respect to placebo by treatment arm and baseline CDR-severity. The changes in ADAS-cog from baseline to 24 weeks in all subjects are plotted in Fig. 2A. The lower dose of $69 \mathrm{mg}$ /day did not differ statistically from placebo. Dose-dependent formulation and absorption factors affecting the highest strength capsules [17] confound interpretation of the $228 \mathrm{mg} /$ day nominal dose group on this and all other outcome measures and are discussed further below. In the absence of placebo decline in subjects with mild disease over 24 weeks, no treatment benefit with MT could be observed. Subjects with moderate disease declined by an average of 4.3 ADAS-cog units over 24 weeks. The $138 \mathrm{mg}$ MT/day dose was effective in preventing clinical decline and the treatment effect was statistically significant (Table $2 ; p=0.008$, corrected $p=0.047$ ). Therefore, the conclusion of the pre-specified primary efficacy analysis in the mITT population is that treatment at $138 \mathrm{mg} /$ day is effective.

\section{Analyses of secondary clinical outcomes at 24 weeks}

The plots of change in ADCS-CGIC and MMSE from baseline to 24 weeks are provided in Fig. $2 \mathrm{~B}$ and C. Both analyses showed a statistically significant treatment 
Table 1

Subject baseline demographics and clinical characteristics

\begin{tabular}{|c|c|c|c|c|c|}
\hline Characteristic & $\begin{array}{l}\text { Placebo } \\
(n=92)\end{array}$ & $\begin{array}{c}69 \mathrm{mg} / \text { day } \\
(n=59)\end{array}$ & $\begin{array}{c}138 \mathrm{mg} / \text { day } \\
(n=80)\end{array}$ & $\begin{array}{c}228 \mathrm{mg} / \text { day } \\
(n=90)\end{array}$ & $\begin{array}{c}\text { Total } \\
(n=321)\end{array}$ \\
\hline $\begin{array}{l}\text { Age (years): } \\
\text { Mean (SD) }\end{array}$ & $74.6(8.1)$ & $73.4(8.7)$ & $73.8(9.9)$ & $73.3(9.4)$ & $73.8(9.0)$ \\
\hline $\begin{array}{l}\text { Gender: } \\
\text { Male, } n(\%) \\
\text { Female, } n(\%)\end{array}$ & $\begin{array}{l}47(51 \%) \\
45(49 \%)\end{array}$ & $\begin{array}{l}26(44 \%) \\
33(56 \%)\end{array}$ & $\begin{array}{l}33(41 \%) \\
47(59 \%)\end{array}$ & $\begin{array}{l}43(48 \%) \\
47(52 \%)\end{array}$ & $\begin{array}{l}149(46 \%) \\
172(54 \%)\end{array}$ \\
\hline $\begin{array}{l}\text { Race: } \\
\text { Afro-Caribbean, } n(\%) \\
\text { Asian, } n(\%) \\
\text { Caucasian, } n(\%)\end{array}$ & $\begin{array}{c}1(1 \%) \\
8(9 \%) \\
83(90 \%)\end{array}$ & $\begin{array}{c}0(0 \%) \\
1(2 \%) \\
58(98 \%)\end{array}$ & $\begin{array}{c}0(0 \%) \\
8(10 \%) \\
72(90 \%)\end{array}$ & $\begin{array}{c}0(0 \%) \\
6(7 \%) \\
84(93 \%)\end{array}$ & $\begin{aligned} & 1(0 \%) \\
& 23(7 \%) \\
& 297(93 \%)\end{aligned}$ \\
\hline $\begin{array}{l}\text { Years since diagnosis: } \\
\text { Mean (SD) }\end{array}$ & $0.86(1.18)$ & $1.00(1.47)$ & $0.89(1.46)$ & $0.85(1.11)$ & $0.89(1.29)$ \\
\hline $\begin{array}{l}\text { Dementia severity: } \\
\text { CDR mild, } n(\%) \\
\text { CDR moderate, } n(\%)\end{array}$ & $\begin{array}{l}72(78 \%) \\
20(22 \%)\end{array}$ & $\begin{array}{l}41(69 \%) \\
18(31 \%)\end{array}$ & $\begin{array}{l}63(79 \%) \\
17(21 \%)\end{array}$ & $\begin{array}{l}76(84 \%) \\
14(16 \%)\end{array}$ & $\begin{array}{r}252(79 \%) \\
69(21 \%)\end{array}$ \\
\hline $\begin{array}{l}\text { MMSE: } \\
\text { Mean (SD) }\end{array}$ & $19.6(4.6)$ & $18.5(4.7)$ & $19.7(4.6)$ & $19.4(4.6)$ & $19.4(4.6)$ \\
\hline $\begin{array}{l}\text { MMSE severity: } \\
\text { MMSE<20, } n(\%) \\
\text { MMSE } \geq 20, n(\%)\end{array}$ & $\begin{array}{l}44(47.8) \\
48(52.2)\end{array}$ & $\begin{array}{l}28(47.5) \\
31(52.5)\end{array}$ & $\begin{array}{l}36(45.1) \\
44(54.9)\end{array}$ & $\begin{array}{l}42(46.7) \\
48(53.3)\end{array}$ & $\begin{array}{l}150(46.7) \\
171(53.3)\end{array}$ \\
\hline $\begin{array}{l}\text { ADAS-Cog: } \\
\text { Mean (SD) }\end{array}$ & $24.5(10.4)$ & $26.9(10.5)$ & $23.3(8.9)$ & $24.7(11.0)$ & $24.6(10.3)$ \\
\hline
\end{tabular}

ADAS-Cog, Alzheimer's Disease Assessment Scale - Cognitive subscale; CDR, Clinical Dementia Rating; MMSE, Mini-Mental State Examination; SD, standard deviation.

Table 2

Change from baseline in ADAS-Cog score and MT treatment effect for subjects with mild and moderate disease severity at 24 weeks

\begin{tabular}{|c|c|c|c|c|c|}
\hline & \multicolumn{2}{|c|}{ Change from baseline } & \multicolumn{3}{|c|}{ Treatment effect } \\
\hline & Estimate $(95 \% \mathrm{CI})$ & $p$ & Estimate $(95 \% \mathrm{CI})$ & $p$ & $p$-adj \\
\hline \multicolumn{6}{|l|}{ MILD } \\
\hline Placebo & $-0.14(-1.40,1.11)$ & 0.826 & & & \\
\hline $69 \mathrm{mg} /$ day & $0.91(-0.82,2.63)$ & 0.301 & $1.05(-1.08,3.17)$ & $0 \cdot 333$ & 1 \\
\hline $138 \mathrm{mg} /$ day & $-0.32(-1.74,1.10)$ & 0.654 & $-0.18(-2.06,1.69)$ & 0.846 & 1 \\
\hline $228 \mathrm{mg} /$ day & $-0.87(-2.15,0.40)$ & 0.347 & $-0.73(-2.51,1.05)$ & 0.419 & 1 \\
\hline \multicolumn{6}{|c|}{ MODERATE } \\
\hline Placebo & $4.35(1.78,6.91)$ & 0.001 & & & \\
\hline $69 \mathrm{mg} /$ day & $1.35(-1.32,4.01)$ & 0.32 & $-3.00(-6.47,0.47)$ & 0.09 & 0.325 \\
\hline $138 \mathrm{mg} /$ day & $-1.08(-4.36,2.21)$ & 0.52 & $-5.42(-9.44,-1.41)$ & 0.008 & 0.047 \\
\hline $228 \mathrm{mg} /$ day & $3.95(-0.64,7.26)$ & 0.019 & $-0.39(-4.28,3.50)$ & 0.843 & 1 \\
\hline
\end{tabular}

The column labelled " $p$-adj" provides the adjusted $p$-values after Westfall/Bonferroni correction for multiple comparisons with 6 dose/severity levels. Also shown are the change from baseline in each of the four study arms at each of two levels of baseline CDR-severity, and the $p$-value for testing if the change from baseline differs significantly from zero. CI, confidence interval.

effect at the $138 \mathrm{mg} /$ day dose in moderate subjects. For the continuous analysis of ADCS-CGIC, the effect size was 1.29 units $(95 \% \mathrm{CI}=[0.43,2.16] ; p=0.0036$; corrected $p=0.021)$; in the categorical analysis, the effect size was $2.17 \log$-odds units $(95 \% \mathrm{CI}=[0.40,4.32]$; $p=0.025$; corrected $p=0.14$; odds-ratio $=8.8$ ). Similar results were found for change in MMSE score from baseline. The effect size was 3.79 units $(95 \% \mathrm{CI}=[1.16$, 6.41]; $p=0.0048$; corrected $p=0.028)$. No other secondary clinical outcome measures were significant. No change from baseline was observed on any scale in mild subjects receiving placebo.

\section{Imaging outcomes at 24 weeks}

Change in rCBF over approximately 24 weeks was analyzed as a secondary outcome in a subset of 135 subjects randomized to sites with SPECT imaging capability. Plots of change in mean rCBF for mild and moderate subjects are provided in Fig. 2D. The analysis of mean change in $\mathrm{rCBF}$ averaged across all ROIs is provided in Table 3. SPECT imaging was sufficiently sensitive to show significant placebo decline in mild subjects. There was significantly less decline in $\mathrm{rCBF}$ following treatment with MT $138 \mathrm{mg}$ and 

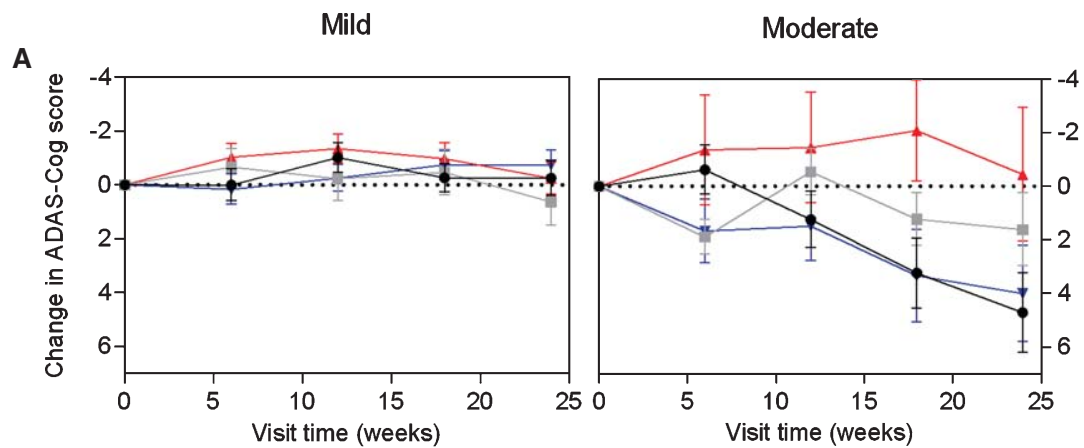

B
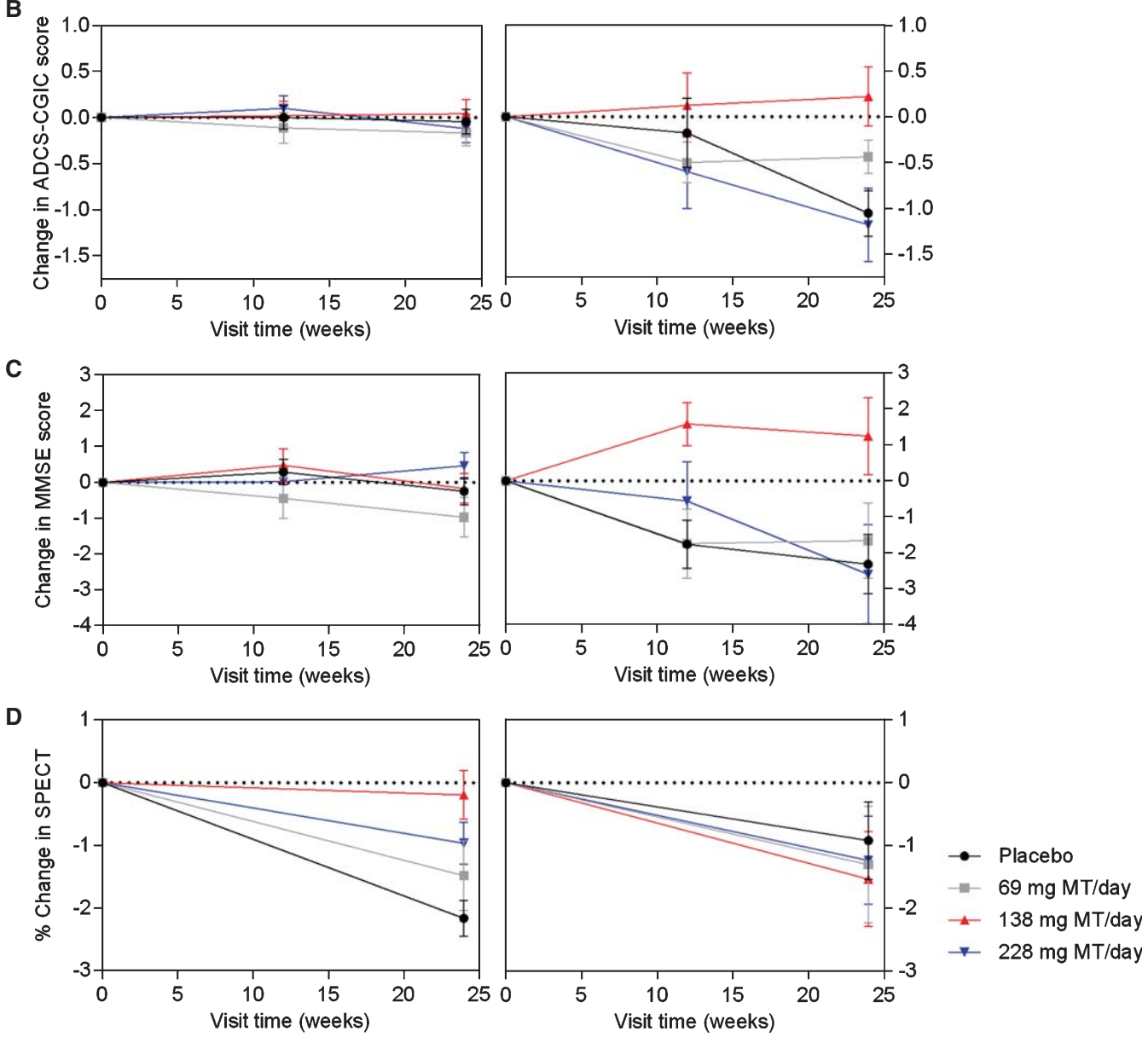

Fig. 2. Clinical and imaging outcomes at 24 weeks for mild and moderate AD.

$228 \mathrm{mg} /$ day nominal doses (corrected $p<0.001$ and 0.031 , respectively). The effect size at $138 \mathrm{mg} /$ day was $91 \%$ of the decline in the corresponding placebo group. In moderate subjects, known to have more advanced perfusion deficits [25], the further placebo decline was non-significant and there was no evidence of treatment benefit.

In the analysis of $\mathrm{rCBF}$ change in individual ROIs (Fig. 3A), mild subjects receiving placebo had significant $\mathrm{rCBF}$ decline in all regions. At the $138 \mathrm{mg} /$ day dose, all regions other than the left frontal lobe were significantly different from placebo at the $p<0.05$ level. In the SPM analysis, the regions with statistically significant differences relative to placebo in subjects receiving any does of MT are illustrated in Fig. 3B, the differences being greatest bilaterally in the medial temporal and temporoparietal regions. 
Table 3

Percentage change from baseline in relative cerebral blood flow (rCBF, normalized to cerebellum) and MTC treatment effect for subjects with mild and moderate disease severity after mean 20 weeks of treatment

\begin{tabular}{|c|c|c|c|c|c|}
\hline & \multicolumn{2}{|c|}{ Change from baseline } & \multicolumn{3}{|c|}{ Treatment effect } \\
\hline & Estimate $(95 \% \mathrm{CI})$ & $p$ & Estimate $(95 \% \mathrm{CI})$ & $p$ & $p$-adj \\
\hline \multicolumn{6}{|l|}{ MILD } \\
\hline Placebo & $-2.16(-2.72,-1.61)$ & $<0.001$ & & & \\
\hline $69 \mathrm{mg} /$ day & $-1.48(-2.57,-0.39)$ & 0.008 & $0.62(-0.54,1.91)$ & 0.275 & 0.697 \\
\hline $138 \mathrm{mg} /$ day & $-0.19(-0.96,0.57)$ & 0.621 & $1.97(1.02,2.92)$ & $<0.001$ & $<0.001$ \\
\hline 228 mg/day & $-0.96(-1.62,0.30)$ & 0.004 & $1.12(0.34,2.06)$ & 0.006 & 0.031 \\
\hline \multicolumn{6}{|l|}{ MODERATE } \\
\hline Placebo & $-0.92(-2.14,0.30)$ & 0.138 & & & \\
\hline $69 \mathrm{mg} /$ day & $-1.30(-3.12,0.52)$ & 0.16 & $-0.38(-2.59,1.82)$ & 0.733 & 0.923 \\
\hline $138 \mathrm{mg} /$ day & $-1.53(-3.01,-0.05)$ & 0.043 & $-0.61(-2.51,1.29)$ & 0.529 & 0.877 \\
\hline $228 \mathrm{mg} /$ day & $-0.012(-2.62,0.14)$ & 0.079 & $-0.32(-2.17,0.15)$ & 0.737 & 0.923 \\
\hline
\end{tabular}

$p$-adj, adjusted $p$-value after Westfall/Bonferroni correction for multiple comparisons with 6 dose/severity levels. CI, confidence interval.

\section{Exploratory post hoc analysis of ADAS-cog change during first extension phase}

With continued treatment for up to 50 weeks, decline was evident in subjects who entered the study with mild disease and were randomized to placebo (and then converted after 24 weeks to capsules with dose-dependent delivery limitations [17]). Patients randomized to MT $138 \mathrm{mg} /$ day, whether mild or moderate at baseline, did not decline and there was a statistically significant treatment benefit of 2.8 to 5.2 ADAS-cog units in mild and moderate subjects, respectively (see Table 4). These effect sizes represent $96 \%$ and $91 \%$, respectively, of the decline seen in the corresponding control arms.

The ADAS-cog effect sizes in mild subjects at 50 weeks reported in Table 4 were compared with imaging effect sizes observed in mild subjects at approximately 24 weeks reported in Table 3. As can be seen from Fig. 4, the $138 \mathrm{mg} /$ day dose was the most effective dose in both modalities. The mean treatment benefit seen by SPECT scan at approximately 24 weeks in mild subjects was highly correlated with the mean clinical effect size measured on the ADAS-cog scale in mild subjects at 50 weeks $(r=0.989)$.

\section{Safety}

Table 5 provides an overview of treatment emergent AEs, during the placebo-controlled and E1/E2 periods, most of which were considered moderate or mild. The most commonly reported AEs (incidence $\geq 5 \%$ ) in MTC-treated subjects included gastrointestinal disorders (primarily diarrhea), renal and urinary disorders (primarily dysuria and frequency), and falls (Table 6 and Supplementary Material S5). A larger proportion of subjects randomized to MTC experienced at least one AE leading to interruption of study drug or permanent discontinuation compared with those randomized to placebo by 24 weeks. The overall incidence of AEs and AEs requiring a change in dosing was greatest at the $138 \mathrm{mg} /$ day dose.

Eight deaths were reported while participating in the study or shortly after discontinuing. Of the six deaths which occurred in MTC-treated subjects, one was from cancer and five were of a cardiovascular or hemorrhagic etiology in subjects with known risk factors; none were attributed to MTC.

No changes of clinical significance were observed in any routine clinical chemistry parameters in any treatment group. Treatment with MTC produced dosedependent decreases in red cell count and hemoglobin and increases in methemoglobin (Fig. 5; Supplementary Material S6). There were 4 cases (of 307 exposed to MTC) with methemoglobin greater than $3.5 \%$ (a threshold set for withdrawal of treatment) which resolved on cessation of treatment. There were no cases of clinically significant anemia. Initial dosedependent decreases in white-blood cell counts were also observed which did not progress beyond 24 weeks (Supplementary Material S7).

\section{Post-hoc dose-response analyses}

The response profiles with respect to nominal dose for the ADAS-cog effect at 24 weeks (Fig. 6A), the SPECT scan effect at approximately 24 weeks (Fig. 6B), the ADAS-cog effect at 50 weeks (Fig. 6 C), and the percentage of subjects with at least one $\mathrm{AE}$ leading to discontinuation or dose interruption at 24 weeks (Fig. 6D) show that the effects at the $228 \mathrm{mg} /$ day nominal dose were consistently less than those at the $138 \mathrm{mg} /$ day dose on all outcomes. 
A

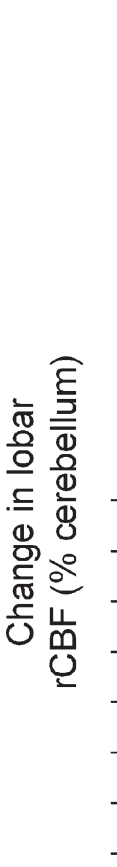

B

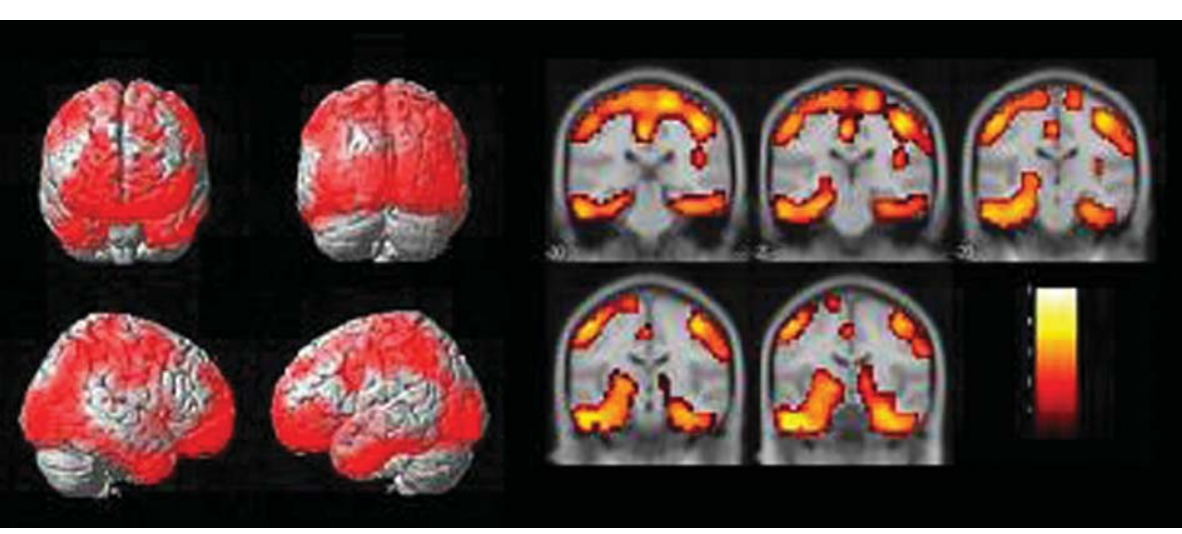

Left Temporal Lobe

Left Parietal Lobe

Left Occipital Lobe

Left Frontal Lobe

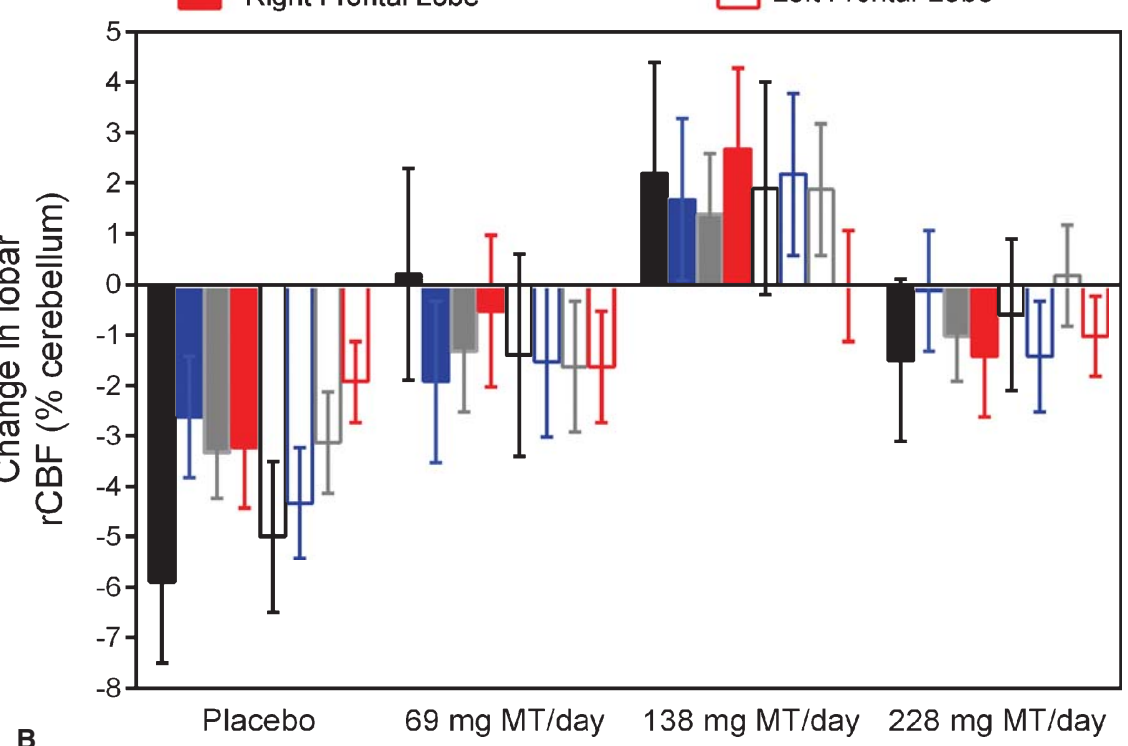

Fig. 3. Percentage change in rCBF SPECT adjusted mean values (normalized to the cerebellum) between baseline and follow-up in mild subjects. A) Differences with respect to placebo were significant at $p<0.05$ for the $69 \mathrm{mg} /$ day dose only in the right temporal lobe, for the $138 \mathrm{mg} / \mathrm{day}$ dose in all lobes except the left frontal lobe, and for the $228 \mathrm{mg} /$ day dose in right and left temporal lobes and in left occipital lobe. B) Results of statistical parametric mapping comparison of change in blood flow between those receiving MTC versus placebo in mild AD subjects. The significant differences are in areas of the brain typically involved with neurofibrillary tangle pathology, i.e., treatment with MT has resulted in significantly less blood flow decline (or in some preservation of blood flow) in colored regions.

The $100 \mathrm{mg}$ MTC gelatin capsule formulation used to deliver the $152 \mathrm{mg}$ and $228 \mathrm{mg}$ MT/day nominal doses was known, at the time that the study was initiated, to sufferfromadose-dependentdissolutionlimitationin water and simulated gastric fluid, although not in simulated intestinal fluid. In addition, a subsequent fed/fasting study showed that there was a dose-dependent limitation in the absorption of MT given as MTC with food, affecting particularly the $100 \mathrm{mgMTC}$ Mnit dose that was independent of the formulation defect. Taking account of both of these factors, the calculated total dose of MT available for absorption is shown in Fig. 7A, comprising MT released within 60 min in water or simulated gastric fluid, or after $60 \mathrm{~min}$ and released in simulated intestinal fluid. The totalavailabledoseishighly correlated with the SPECT scan effect size at 24 weeks (Fig. 7B, $r=0.974$ ), theADAS-cogeffectsizeat50weeks(Fig.7 C, $r=0.983$ ) and the percentage of subjects with at least one AE lead- 
Table 4

Change from baseline in ADAS-Cog score and MT treatment effect for subjects with mild and moderate disease severity at 50 weeks

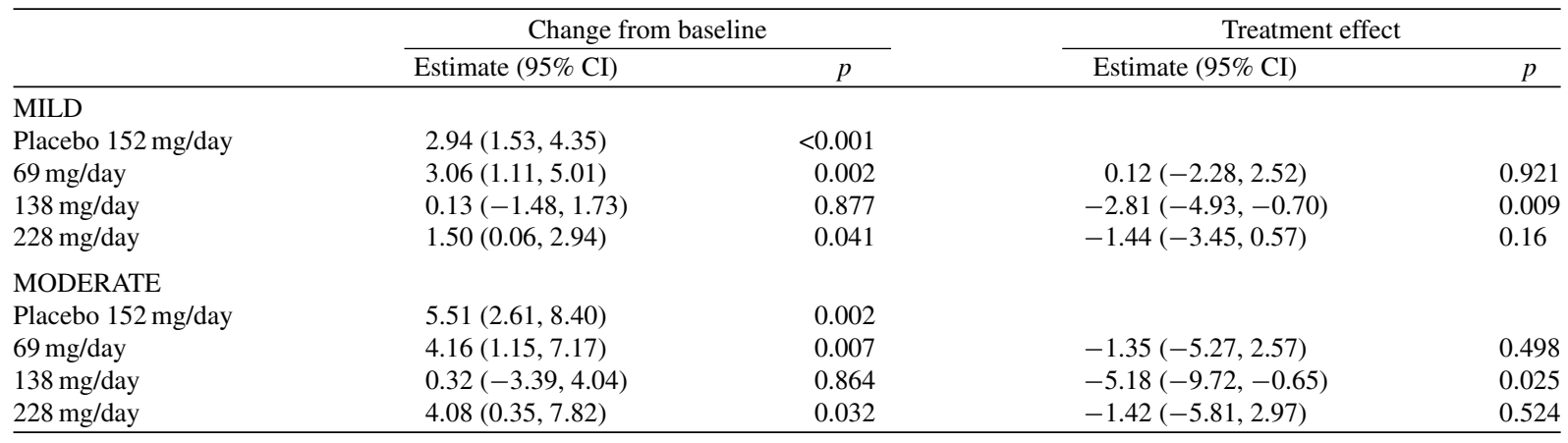

CI, confidence interval.

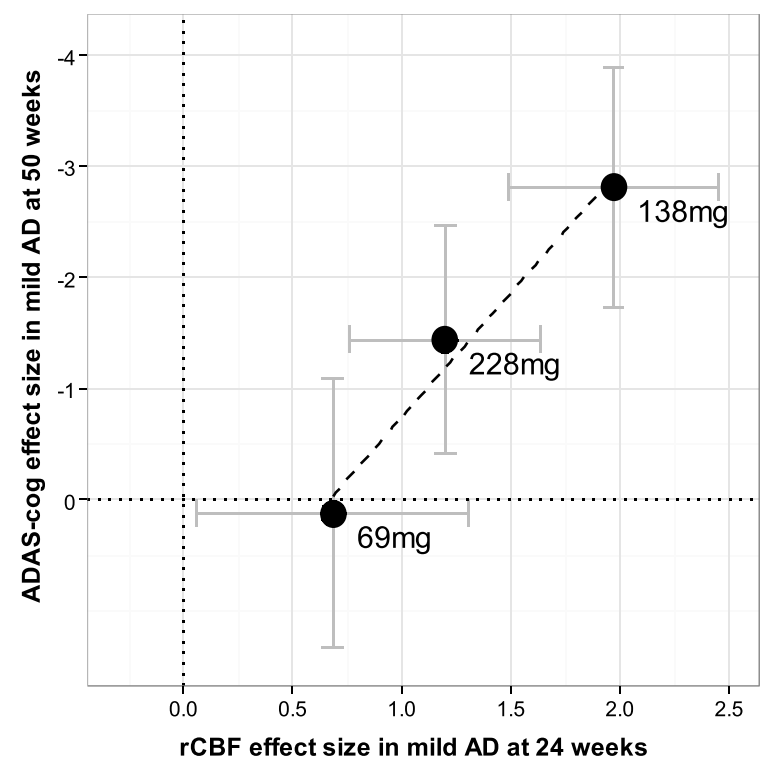

Fig. 4. Comparison of ADAS-cog effect size in mild AD at 50 weeks with the imaging effect sizes at approximately 24 weeks in mild $\mathrm{AD}$.

Table 5

Summary of treatment-emergent adverse events (AEs)

\begin{tabular}{|c|c|c|c|c|c|c|}
\hline & \multicolumn{4}{|c|}{24 week study } & \multirow{2}{*}{$\begin{array}{c}\text { E1 } \\
\text { All MT } \\
n=227\end{array}$} & \multirow{2}{*}{$\begin{array}{c}\text { E2 } \\
\text { All MT } \\
n=170\end{array}$} \\
\hline & $\begin{array}{c}\text { Placebo } \\
n=92\end{array}$ & $\begin{array}{l}69 \mathrm{mg} \\
n=59\end{array}$ & $\begin{array}{c}138 \mathrm{mg} \\
n=80\end{array}$ & $\begin{array}{c}228 \mathrm{mg} \\
n=90\end{array}$ & & \\
\hline Total number of AEs & 161 & 142 & 198 & 248 & 322 & 289 \\
\hline At least one AE, $n(\%)$ & $61(66.3)$ & 43 (72.9) & $67(83.7)$ & $70(77.8)$ & $139(61.2)$ & $96(56.5)$ \\
\hline $\begin{array}{l}\text { At least one AE related to study } \\
\text { drug, } n(\%)\end{array}$ & $22(23.9)$ & $30(50.8)$ & $48(60.0)$ & $53(58.9)$ & $65(28.6)$ & $36(21.2)$ \\
\hline At least one severe AE, $n(\%)$ & $4(4.3)$ & $2(3.4)$ & $8(10.0)$ & $8(8.9)$ & $10(4.4)$ & $14(8.2)$ \\
\hline $\begin{array}{l}\text { At least one AE leading to } \\
\text { discontinuation/interruption } \\
\text { of study drug, } n(\%)\end{array}$ & $7(7.6)$ & $12(20.3)$ & $34(42.5)$ & $26(28.9)$ & $36(15.9)$ & $23(13.5)$ \\
\hline $\begin{array}{l}\text { AEs resulting in permanent } \\
\text { discontinuation, } n(\%)\end{array}$ & $4(4.3)$ & $6(10.2)$ & $28(35.0)$ & $21(23.3)$ & $20(8.8)$ & $16(9.4)$ \\
\hline $\begin{array}{l}\text { Treatment emergent severe } \\
\text { AE, } n(\%)\end{array}$ & $12(13.0)$ & $2(3.4)$ & $13(16.3)$ & $11(12.2)$ & $21(9.3)$ & $26(15.3)$ \\
\hline
\end{tabular}

ing to discontinuation or dose interruption at 24 weeks (Fig.7D, $r=0.976$ ). ThecorrelationbetweenADAS-cog effect at 24 weeks and total available dose was weaker $(r=0.664)$, but was better correlated with dose avail- 
Table 6

Number $(\%)$ of subjects with at least one treatment-emergent adverse event (AE) with an incidence of $\geq 5 \%$ of subjects in any treatment group (placebo-controlled safety population)

\begin{tabular}{|c|c|c|c|}
\hline & \multicolumn{2}{|c|}{$\begin{array}{c}\text { All MT } \\
(n=307)\end{array}$} & \multirow{2}{*}{$\begin{array}{c}\text { MT Exposed } \\
\geq 365 \text { days } \\
(n=151)\end{array}$} \\
\hline & All AE & Treatment-related $\mathrm{AE}$ & \\
\hline Number of subjects with at least one AE & $268(87.3 \%)$ & $184(59.9 \%)$ & $80(52.9 \%)$ \\
\hline \multicolumn{4}{|l|}{ Gastrointestinal disorders: } \\
\hline Constipation & $15(4.9 \%)$ & $4(1.3 \%)$ & $1(0.7 \%)$ \\
\hline Diarrhea & $89(29.0 \%)$ & $79(25.7 \%)$ & $7(4.6 \%)$ \\
\hline Dyspepsia & $14(4.6 \%)$ & $9(2.9 \%)$ & $1(0.7 \%)$ \\
\hline Nausea & $20(6.5 \%)$ & $14(4.6 \%)$ & $4(2.6 \%)$ \\
\hline Vomiting & $19(6.2 \%)$ & $14(4.6 \%)$ & $2(1.3 \%)$ \\
\hline Peripheral edema & $14(4.6 \%)$ & $3(1.0 \%)$ & $2(1.3 \%)$ \\
\hline \multicolumn{4}{|l|}{ Infections and infestations: } \\
\hline Lower respiratory tract infection & $27(8.8 \%)$ & $1(0.3 \%)$ & $6(4.0 \%)$ \\
\hline Urinary tract infection & $27(8.8 \%)$ & $3(1.0 \%)$ & $9(6.0 \%)$ \\
\hline Fall & $29(9.4 \%)$ & $6(2.0 \%)$ & $5(3.3 \%)$ \\
\hline Dizziness & $22(7.2 \%)$ & $8(2.6 \%)$ & $4(2.6 \%)$ \\
\hline Depression & $13(4.2 \%)$ & $3(1.0 \%)$ & $2(1.3 \%)$ \\
\hline \multicolumn{4}{|l|}{ Renal and urinary disorders: } \\
\hline Dysuria & $21(6.8 \%)$ & $20(6.5 \%)$ & $1(0.7 \%)$ \\
\hline Micturition urgency & $20(6.5 \%)$ & $20(6.5 \%)$ & $1(0.7 \%)$ \\
\hline Pollakiuria & $40(13.0 \%)$ & $39(12.7 \%)$ & $3(1.0 \%)$ \\
\hline Urinary incontinence & $18(5.9 \%)$ & $15(4.9 \%)$ & $1(0.7 \%)$ \\
\hline Rash & $16(5.2 \%)$ & $6(2.0 \%)$ & $5(3.3 \%)$ \\
\hline
\end{tabular}

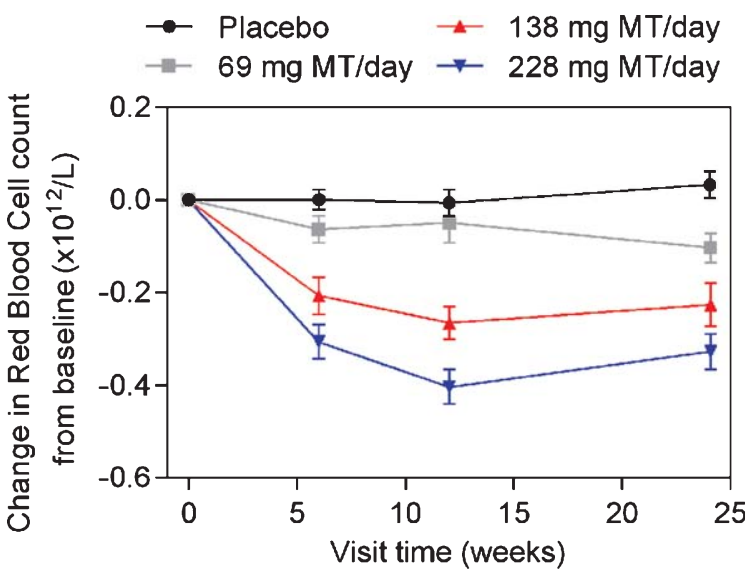

Fig. 5. Change in red blood cell count from baseline to 24 weeks by dose.

able for absorption within $60 \mathrm{~min}$ (Fig. 8A, $r=0.835$ ). Reduction in red blood cell count at 24 weeks was highly correlated withdoseavailableforabsorptionafter60 $\mathrm{min}$ (Fig. 8B, $r=0.955$ ).

\section{DISCUSSION}

The primary aim of this study was to determine whether treatment with a TAI has potential utility in the treatment of $\mathrm{AD}$ and, if so, to determine the minimum safe and effective dose and likely treatment effect size for further investigation. The primary efficacy analysis at 24 weeks showed that treatment with MT $138 \mathrm{mg} /$ day is the minimum effective dose required to prevent disease progression in subjects with baseline disease of moderate severity. Efficacy was confirmed in an independent population using more sensitive imaging measures in subjects with baseline mild disease. Specifically, in the pre-specified primary efficacy analysis model, treatment with $138 \mathrm{mg}$ /day produced statistically significant benefit with respect to placebo on the ADAS-cog scale (corrected $p=0.047$ ) at 24 weeks in patients with moderate $\mathrm{AD}$ at baseline, even after correcting conservatively for multiple comparisons. Significant effects were also seen on the ADCS-CGIC and MMSE secondary outcome scales. A significant treatment effect was seen at the same dose on the overall $\mathrm{rCBF}$ imaging outcome in a separate population (mild subjects) at approximately 24 weeks after applying similar corrections. Similar conclusions are drawn if one uses a linear mixed effects analysis with an unstructured correlation matrix without imputation. In these analyses, used in current phase 3 clinical trials, the treatment effect at the $138 \mathrm{mg} /$ day dose was significant in moderate subjects at 24 weeks $(p=0.023)$ and in the combined $\mathrm{mild} /$ moderate population at 50 weeks $(p=0.0073)$. 
A

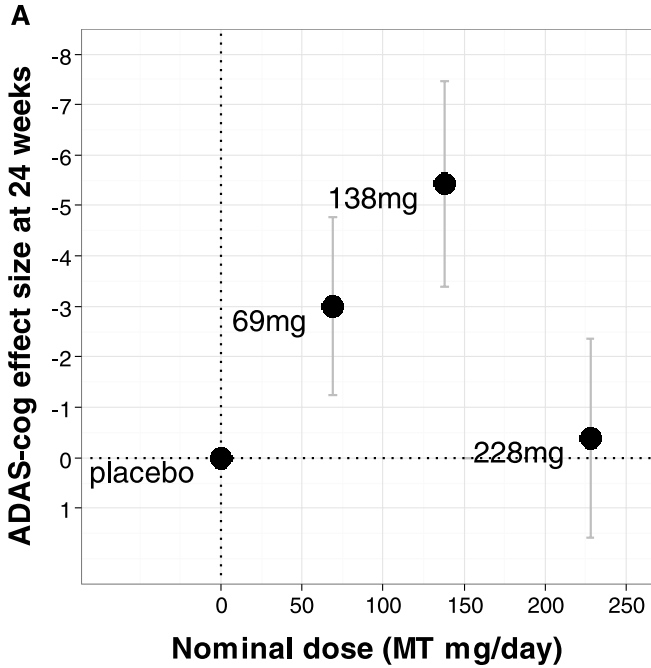

C

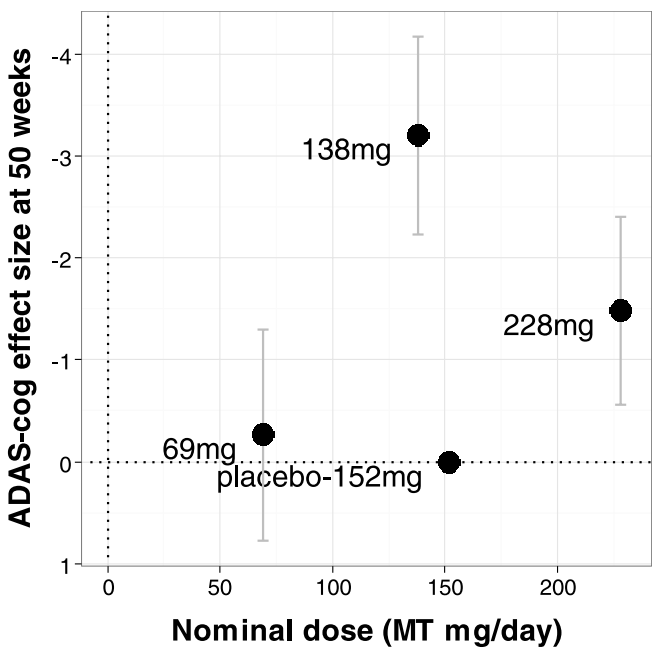

B

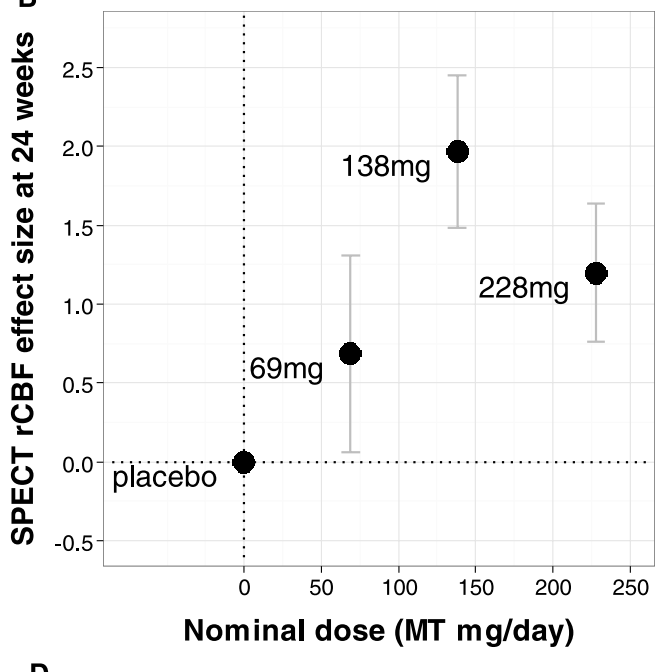

D

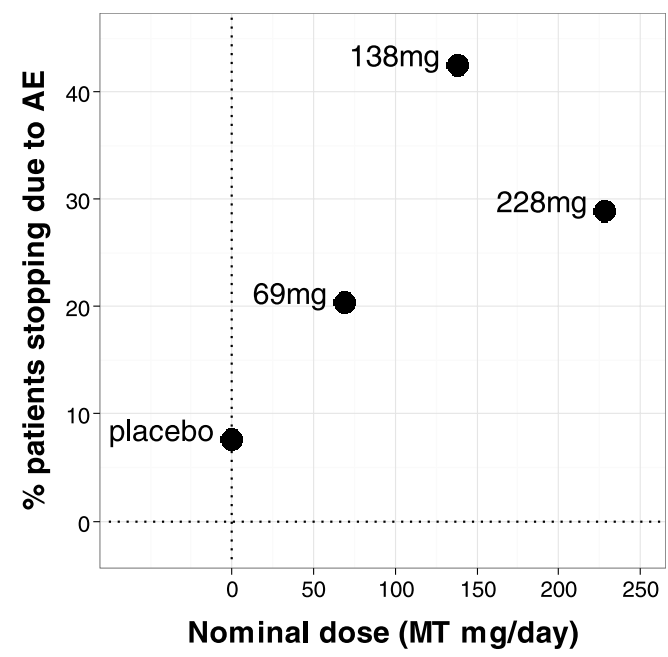

Fig. 6. There is no dose-response relationship for the $228 \mathrm{mg} / \mathrm{day}$ or the $152 \mathrm{mg} /$ day doses of MT delivered via $100 \mathrm{mg}$ MTC capsules for cognitive effects, SPECT rCBF effects or frequency of adverse events. A) ADAS-cog effect size at 24 weeks in moderate subjects versus nominal dose. B) SPECT rCBF effect size at 24 weeks in mild subjects versus nominal dose. C) ADAS-cog effect size at 50 weeks in all subjects versus nominal dose. D) Percentage of subjects with adverse events resulting in dose interruption or discontinuation versus nominal dose.

None of the clinical, imaging, or overall safety effects increased monotonically with respect to the nominal dose. In the absence of any prior knowledge of dose-effect, the Westfall correction for multiple comparisons was specified a priori because it does not assume monotonic dose-response and permits independent statements to be made about effectiveness at any dose/severity level compared to $5 \%$ for a test with family-wise type 1 error probability of $5 \%$.

The failure of the $228 \mathrm{mg}$ /day nominal dose of MT was entirely unexpected, and has taken a considerable body of work to understand (reported in [17]). In summary, MT is a redox molecule and, depending on environmental conditions (e.g., pH, oxygen, reducing agents), exists in equilibrium between a reduced (leuco-methylthioninium, LMT) and oxidized form $\left(\mathrm{MT}^{+}\right)$. As the chloride salt (MTC) used in the phase 2 trial, MT exists entirely in the $\mathrm{MT}^{+}$form in an oxygen atmosphere. Active conversion to the LMT form is required to permit absorption by passive diffusion $[17,26]$. This conversion occurs optimally in the stomach, likely due to the $\mathrm{pH}$ dependence of the MT redox potential [27]. MTC is therefore a pro-drug, and the absorption and disposition of MT depend both on the $\mathrm{fed} /$ fasting status and on dissolution time of the formulation administered [17]. 
A

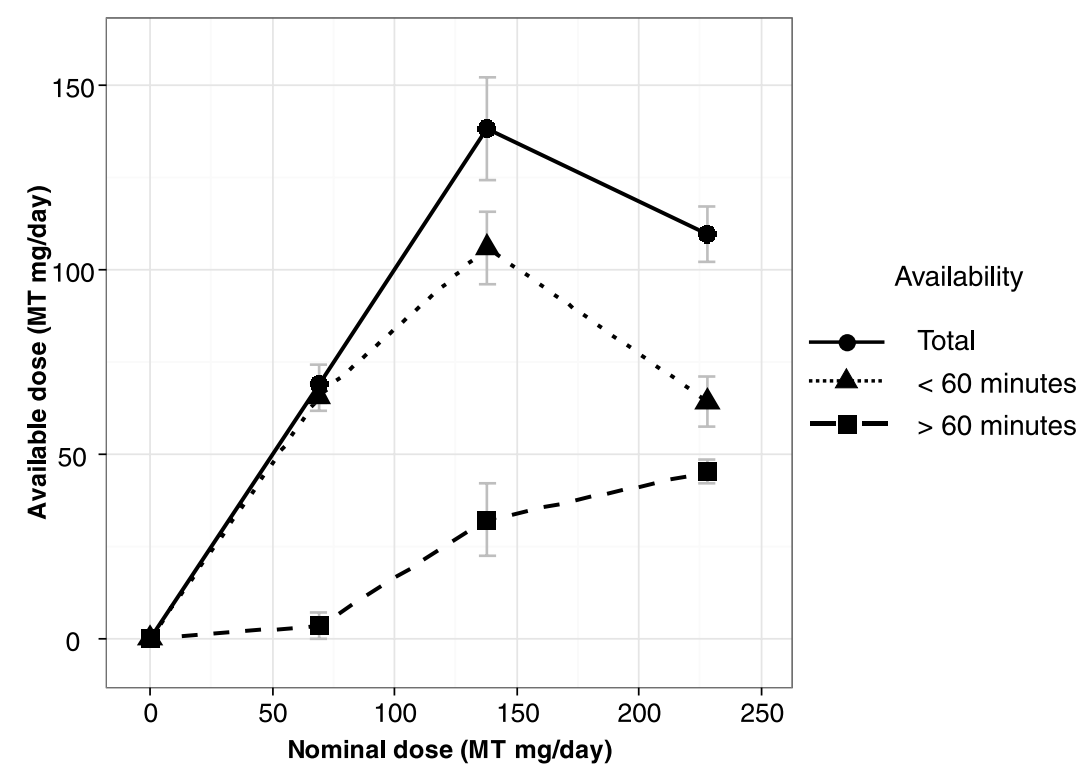

B

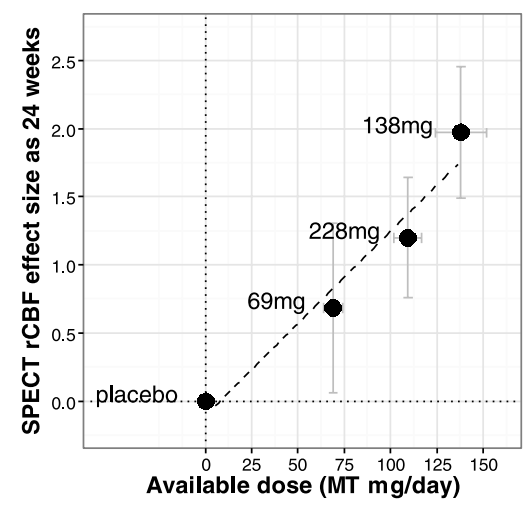

C

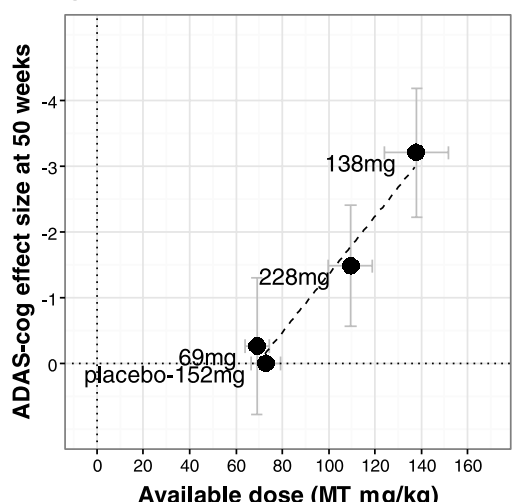

D

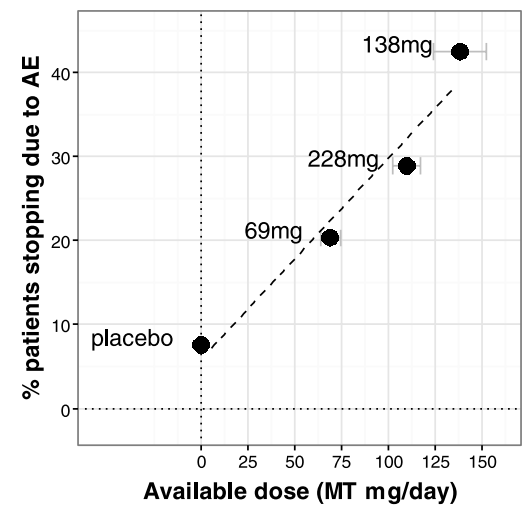

Fig. 7. There are simple dose-response relationships for calculated total dose which can be absorbed in the presence of food. A) Total available dose and dose available for absorption within $60 \mathrm{~min}$ or after $60 \mathrm{~min}$. B) SPECT rCBF effect size at 24 weeks in mild subjects versus total available dose $(r=0.974)$. C) ADAS-cog effect size at 50 weeks in all subjects versus total available dose $(r=0.983)$. D) Percentage of subjects with at least one adverse event resulting in dose interruption or discontinuation versus total available dose $(r=0.976)$. [(A) is reproduced, with permission, from Baddeley et al. [17]].

MTC is poorly tolerated in the absence of food and is subject to dose-dependent absorption interference when administered with food. This effect proved to be the predominant determinant of dose-response for the SPECT scan effect at 24 weeks, the ADAS-cog effect at 50 weeks, and the frequency of AEs leading to dose interruption/discontinuation. The dose-response relationships with respect to available dose are monotonic and linear with correlation coefficients for mean effects all greater than 0.97. Dissolution time within or after $60 \mathrm{~min}$ is a further contributory factor accounting for the ADAS-cog effect at 24 weeks $(r=0.835)$ and the hematological effect of MT $(r=0.955)$. This suggests a partial dissociation between cognitive and hematological effects that depends on where in the gut MT is available for release, presumably reflecting differential redox processing. It should be noted that there are also strong correlations between the dose available for absorption within $60 \mathrm{~min}$ and the SPECT scan effect at 24 weeks $(r=0.947)$, the ADAS-cog effect at 50 weeks $(r=0.927)$, and the frequency of AEs leading to dose interruption/discontinuation $(r=0.953)$. Of the nominal dose of $228 \mathrm{mg} /$ day, only $109 \mathrm{mg} /$ day was available for absorption with food. Therefore, the most effective dose of $138 \mathrm{mg} /$ day simply represents the highest available dose tested in this study. In summary, the clinical, 
A

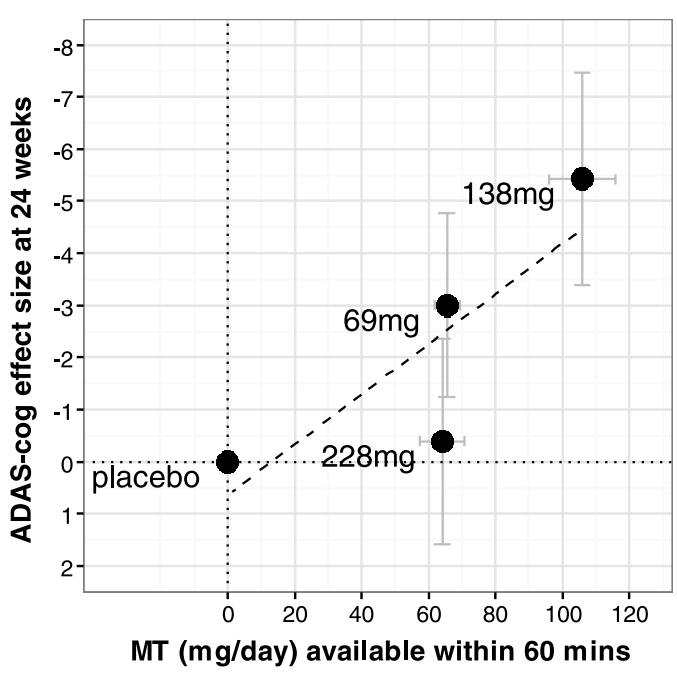

B

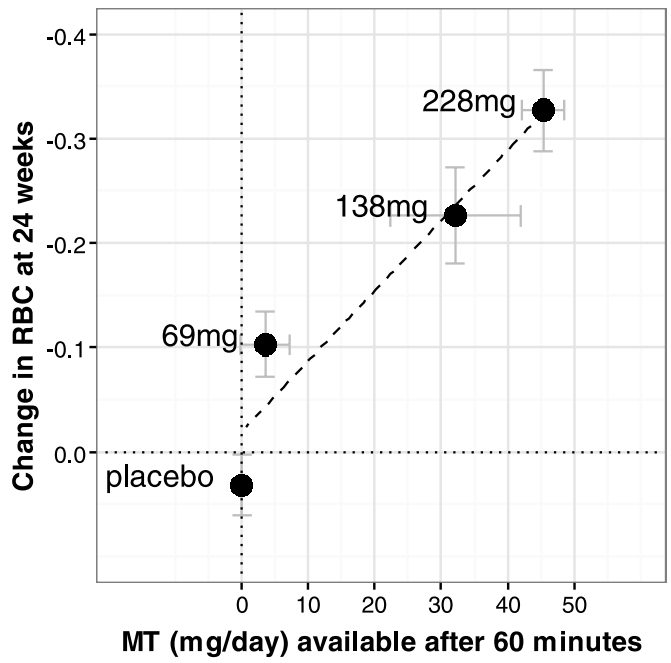

Fig. 8. Partial dissociation of cognitive and hematological effects at 24 weeks depends on dissolution time in vitro. A) ADAS-cog effect size at 24 weeks versus dose available for absorption within $60 \mathrm{~min}(r=0.835)$. B) Decline in RBC count $\left(\mathrm{x} 10^{12} / \mathrm{L}\right)$ from baseline versus dose available for absorption after $60 \mathrm{~min}(r=0.955)$.

imaging, and safety effects of MT are highly determined by a combination of redox processing in the gut and ability to absorb MT in the presence of food when given in the oxidized $\mathrm{MT}^{+}$form as MTC.

The complex factors affecting absorption and disposition of MT redox forms were entirely unknown at the time the study was designed, or for the last 100 years that MTC has been in clinical use. However, the unexpected dose-dependent limitations in the absorption of the $100 \mathrm{mg}$ MTC capsule made the blinded extension phase of the study to 52 weeks more informative than would otherwise have been the case. During weeks 24-50, subjects originally randomized to placebo received a nominal dose of $152 \mathrm{mg} \mathrm{MT/day}$ administered as $100 \mathrm{mg}$ MTC capsules given twice daily and an additional placebo capsule to maintain the blind. The intention was to obtain preliminary information regarding twice daily dosing using the highest dose capsules. Since these were particularly affected by absorption and dissolution limitations, only $73 \mathrm{mg} /$ day of the $152 \mathrm{mg}$ /day nominal dose administered during weeks 24-50 was available for absorption with food. Therefore, subjects originally randomized to placebo during the first 24 weeks and progressing to the $152 \mathrm{mg} /$ day nominal dose during weeks $24-50$ provided a relatively inactive control arm through to 50 weeks which permitted informative post-hoc comparisons to be made with respect to subjects randomized to active doses who continued with their original randomized doses for 50 weeks.
The placebo decline not seen in mild subjects at 24 weeks was 2.9 ADAS-cog units at 50 weeks in the control arm, comparable to the mean placebo decline $(3.5 \pm 1.8$ units [mean \pm S.E.]) seen in a meta-analysis of studies in mild AD subjects at 12 months [28-35] performed by two of the authors (CMW, DJW). By contrast, the mean decline seen in mild subjects receiving the $138 \mathrm{mg} /$ day dose was close to zero, implying an effect size equivalent to $96 \%$ of the decline seen in the control arm and statistically significant $(p=0.009)$. Similarly, the effect size at this dose in moderate subjects was $94 \%$ of the decline seen in the control arm at 50 weeks $(p=0.025)$. This indicates that notwithstanding the differences in decline relative to severity seen in the control arm, the corresponding treatment effect sizes appear to represent a constant fraction of decline in the control arm, as would be expected for a disease-modifying treatment.

It is intriguing that the mean effect size seen by SPECT scan in the absence of apparent clinical benefit at 24 weeks in mild subjects was highly correlated with the mean clinical effect in mild subjects seen on the ADAS-cog scale at 50 weeks $(r=0.989)$. This suggests that the benefit seen early in the more sensitive functional molecular imaging modality could have potential utility as an early predictor of later clinical benefit. Although FDG-PET is more widely used for functional molecular imaging of the brain in the US, both HMPAO-SPECT and FDG-PET are non-specific tracers that show uptake proportionate to 
cerebral blood flow and glucose uptake, respectively. As such, they are both indirect measures of normal brain metabolism. Their contribution to an imaging diagnosis in $\mathrm{AD}$ is the pattern of reduction in blood flow or glucose uptake in areas of the brain typically affected by tau aggregation pathology [36]. While both provide indirect measures of normal brain metabolic activity (i.e., oxygen and glucose consumption respectively), their ability to demonstrate deficits due to neuropathology is similar [36, 37]. The spatial resolution of PET is higher, but by using voxel-based image analysis methods (as was the case in the present study), both have comparable accuracy [38].

Deficits shown by HMPAO-SPECT in brain regions affected by tau aggregation pathology have been shown to correlate with tau aggregation pathology as measured by Braak stage [36]. The ROI and SPM analyses of $\mathrm{rCBF}$ decline provide a mapping of the regions of treatment benefit to those known to be particularly rich in tangles, notably medial temporal lobe structures and temporoparietal regions [39]. This supports the possibility that the clinical and imaging benefits of MT treatment at $138 \mathrm{mg} /$ day may be due to MT activity as a TAI. Activity as a TAI is consistent with the estimated steady state trough brain concentration of $\mathrm{MT}$ at the $138 \mathrm{mg} /$ day dose $(0.18 \mu \mathrm{M})$ [17], the $\mathrm{IC}_{50}$ value for dissolution of PHFs $(0.16 \mu \mathrm{M})$, the calculated intracellular Ki for TAI activity $(0.12 \mu \mathrm{M})$ (Harrington et al., unpublished results), and the brain concentration range over which MT reverses tau pathology and behavioral deficits in two tau transgenic mouse models (Melis et al., Behav. Pharmacol., in press). We have recently reviewed alternative mechanisms of action of MT that have been proposed in the literature [9]. Most of these, however, are inconsistent with the concentrations of MT that could plausibly be achieved in the brain following oral dosing in humans.

A secondary aim of the study was to explore the safety and tolerability of MT in AD. The safety profile observed in this study is in keeping with previous reports of oral MTC use [13-15, 21]. Gastrointestinal and urological effects are the most common; these were also the most common reason for discontinuation. MTC is known to be associated with dose-related anemia. Effects seen in this study generally were not clinically significant.

There are other important limitations to this study in addition to the formulation and absorption limitations of the highest dose capsules. Although large by phase 2 standards, this exploratory study was designed as dose-finding, with the result that the number of subjects was small in the treatment arm of greatest interest in retrospect. The treatment benefit at $138 \mathrm{mg} /$ day was seen in only 17 moderate subjects in the analysis of ADAS-cog at 24 weeks and in 25 mild subjects by HMPAO-SPECT, although there were 68 subjects in the post-hoc 50-week analysis. Nevertheless, the prespecified primary analysis at 24 weeks has taken these small numbers into account, and statistical significance was achieved only because of the large effect sizes observed. The effect sizes of -5.4 ADAS-cog units and 3.8 MMSE units are clinically meaningful at 24 weeks.

Another potential limitation is the lack of urinary discoloration in the placebo arm at 24 weeks. However, discoloration is known not to be proportional to MTC dose [19], and clinical procedures were implemented to minimize its potential impact on efficacy rating. It is unlikely that this consideration undermines the validity of the efficacy signals observed, as the $228 \mathrm{mg} /$ day and $152 \mathrm{mg} /$ day nominal doses delivered via $100 \mathrm{mg}$ MTC capsules proved to be ineffective despite being absorbed and producing discoloration, hematological changes, and clinical AEs at 24 and 50 weeks. In particular, the treatment effect of the $138 \mathrm{mg} /$ day dose at 50 weeks was determined relative to an available dose of $73 \mathrm{mg} /$ day in the control arm. We have shown that a dose of $8 \mathrm{mg} /$ day is sufficient to cause adequate discoloration of excreta to ensure blinding. Therefore the treatment effect observed at 50 weeks in the $138 \mathrm{mg} /$ day group was not confounded by absence of urinary discoloration in the control arm. Most importantly, the molecular imaging findings provide independent biological confirmation at 24 weeks that the $138 \mathrm{mg} /$ day dose is the most effective.

The benefits seen at 24 weeks were sustained to 50 weeks such that the overall decline in subjects randomized to this dose was not significantly different from zero $(0.27 \pm 0.74$ ADAS-cog units [mean \pm S.E.], $p=0.714)$. From our meta-analysis of previously reported studies, the decline expected in clinical trial populations of mild or moderate $\mathrm{AD}$ at 12 months is $4.4 \pm 1.8$ (mean \pm S.E.). While the efficacy data at 50 weeks, being as they are exploratory and post hoc, cannot support an inferential claim in the same way that the 24 week data can, they are nevertheless informative as a basis for planning confirmatory phase 3 trials. The primary purpose of a phase 2 trial in a new treatment paradigm is to inform the design of confirmatory phase 3 trials by providing an estimate of the expected effect size. Notwithstanding the limitations of the 50-week data, they provide an empirical estimate of effect size at the minimal effective dose expected in a mild/moderate population at 12 months in a linear mixed effects unstructured correction matrix analy- 
sis without imputatoin as approximately $90 \% \pm 35 \%$ (mean \pm S.E.) of the expected placebo decline as a basis for planning further studies.

The present study identified a dose of $138 \mathrm{mg} /$ day as the minimum effective dose required to prevent decline on three clinical outcome measures and on rCBF decline at 24 weeks. The AEs seen at the $138 \mathrm{mg}$ MT/day dose, which were predominantly mild and restricted to the gastrointestinal system and micturition, do not preclude further clinical development. While the results support further confirmatory studies with MT, these cannot be conducted using MTC because of absorption and longer term tolerability limitations. The absorption limitations at the highest nominal dose of $228 \mathrm{mg}$ /day limited delivery to an available dose of $109 \mathrm{mg} /$ day. Therefore, the present study did not permit determination of whether greater efficacy than seen at the $138 \mathrm{mg}$ /day dose is achievable at a higher available dose without significant loss of tolerability or safety. Global phase 3 studies in mild and moderate AD are now fully recruited and will report in 2016. They investigate MT doses in the range $150-250 \mathrm{mg} /$ day using a stable reduced form $\left(\right.$ LMTX $\left.^{\circledR}\right)$ that directly delivers LMT without need for active conversion from $\mathrm{MT}^{+}$, is better tolerated, and does not suffer from the dose-dependent absorption limitations of MTC [17].

\section{ACKNOWLEDGMENTS}

We thank patients and their caregivers for their participation in the study and are indebted to all the investigators involved in the study, particularly Drs. Douglas Fowlie and Donald Mowat for their helpful contributions to the clinical execution of the study in Scotland. We thank Sharon Eastwood, Parexel, for assistance in preparing initial drafts of the manuscript. We acknowledge constructive comments provided by Professors G. Wilcock and S. Gauthier on drafts of the article. CMW, CRH, and JMDS are officers of, and hold beneficial interests in, TauRx Therapeutics. RTS, PB, KK, and DJW are paid consultants to TauRx Therapeutics. The study was financed entirely by TauRx Therapeutics.

Authors' disclosures available online (http://j-alz .com/manuscript-disclosures/14-2874r1).

\section{SUPPLEMENTARY MATERIAL}

The supplementary material is available in the electronic version of this article: http://dx.doi.org/10. 3233/JAD-142874.

\section{REFERENCES}

[1] Alzheimer A (1907) Über eine eigenartige Erkrankung der Hirnrinde. Allg Z Psych Psych-gerich Med 64, 146-148.

[2] Wischik CM, Crowther RA, Stewart M, Roth M (1985) Subunit structure of paired helical filaments in Alzheimer's disease. J Cell Biol 100, 1905-1912.

[3] Wischik CM, Novak M, Edwards PC, Klug A, Tichelaar W, Crowther RA (1988) Structural characterization of the core of the paired helical filament of Alzheimer disease. Proc Natl Acad Sci U S A 85, 4884-4888.

[4] Wischik CM, Novak M, Thøgersen HC, Edwards PC, Runswick MJ, Jakes R, Walker JE, Milstein C, Roth M, Klug A (1988) Isolation of a fragment of tau derived from the core of the paired helical filament of Alzheimer's disease. Proc Natl Acad Sci U S A 85, 4506-4510.

[5] Arriagada PW, Growdon JH, Hedley-White ET, Hyman BT (1992) Neurofibrillary tangles but not senile plaques parallel duration and severity of Alzheimer's disease. Neurology 42, 631-639.

[6] Giannakopoulos P, Herrmann FR, Bussiere T, Bouras C, Kovari E, Perl DP, Morrison JH, Gold G, Hof PR (2003) Tangle and neuron numbers, but not amyloid load, predict cognitive status in Alzheimer's disease. Neurology 60, 1495-1500.

[7] Josephs KA, Whitwell JL, Ahmed Z, Shiung MM, Weigand SD, Knopman DS, Boeve BF, Parisi JE, Petersen RC, Dickson DW, Jack CR (2008) $\beta$-Amyloid burden is not associated with rates of brain atrophy. Ann Neurol 63, 204-212.

[8] Maruyama M, Shimada H, Suhara T, Shinotoh H, Ji B, Maeda J, Zhang M-R, Trojanowski John Q, Lee Virginia MY, Ono M, Masamoto K, Takano H, Sahara N, Iwata N, Okamura N, Furumoto S, Kudo Y, Chang Q, Saido Takaomi C, Takashima A, Lewis J, Jang M-K, Aoki I, Ito H, Higuchi M (2013) Imaging of tau pathology in a tauopathy mouse model and in Alzheimer patients compared to normal controls. Neuron 79, 1094-1108.

[9] Wischik CM, Harrington CR, Storey JMD (2014) Tauaggregation inhibitor therapy for Alzheimer's disease. Biochem Pharmacol 88, 529-539.

[10] Huang Y, Mucke L (2012) Alzheimer mechanisms and therapeutic strategies. Cell 148, 1204-1222.

[11] Wischik CM, Wischik DJ, Storey JMD, Harrington CR (2010) Rationale for tau aggregation inhibitor therapy in Alzheimer's disease and other tauopathies In Emerging Drugs and Targets for Alzheimer's Disease. Volume 1: Beta-amyloid, tau protein and glucose metabolism, Martinez A, ed. Royal Society of Chemistry, Cambridge, pp. 210-232.

[12] Mansouri A, Lurie AA (1993) Concise review: Methemoglobinemia. Am J Hematol 42, 7-12.

[13] Boyce WH, McKinney WM, Long TT, Drach GW (1967) Oral administration of methylene blue to patients with renal calculi. J Urol 97, 783-789.

[14] Naylor GJ, Martin B, Hopwood SE, Watson Y (1986) A twoyear double-blind crossover trial of the prophylactic effect of methylene blue in manic-depressive psychosis. Biol Psychiatry 21, 915-920.

[15] Wein AJ, Benson GS, Raezer DM, Mulholland SG (1976) Oral methylene blue and the dissolution of renal calculi. $J$ Urol 116, 140-141.

[16] Wischik CM, Edwards PC, Lai RYK, Roth M, Harrington CR (1996) Selective inhibition of Alzheimer disease-like tau aggregation by phenothiazines. Proc Natl Acad Sci U S A 93, 11213-11218. 
[17] Baddeley TC, McCaffrey J, Storey JMD, Cheung JKS, Melis V, Horsley D, Harrington CR, Wischik CM, (2015) Complex disposition of methylthioninium redox forms determines efficacy in tau aggregation inhibitor therapy for Alzheimer's disease. J Pharmacol Exp Ther 352, 110-118.

[18] Harrington CR, Louwagie J, Rossau R, Vanmechelen E, Perry RH, Perry EK, Xuereb JH, Roth M, Wischik CM (1994) Influence of apolipoprotein E genotype on senile dementia of the Alzheimer and Lewy body types. Significance for etiological theories of Alzheimer's disease. Am J Pathol 145, 1472-1484.

[19] DiSanto AR, Wagner JG (1972) Pharmacokinetics of highly ionized drugs. II. Methylene blue - absorption, metabolism, and excretion in man and dog after oral administration. $J$ Pharmacol Sci 61, 1086-1090.

[20] Peter C, Hongwan D, Küpfer A, Lauterburg BH (2000) Pharmacokinetics and organ distribution of intravenous and oral methylene blue. Eur J Clin Pharmacol 56, 247-250.

[21] Royal Pharmaceutical Society of Great Britain (2002) Methylene blue. In Martindale: The Complete Drug Reference, Sweetman SC, ed. Pharmaceutical Press, London and Chicago, pp. 1012-1014.

[22] García-Sierra F, Wischik CM, Harrington CR, Luna-Muñoz J, Mena R (2001) Accumulation of C-terminally truncated tau protein associated with vulnerability of the perforant pathway in early stages of neurofibrillary pathology in Alzheimer's disease. J Chem Neuroanat 22, 65-77.

[23] Westfall PH (1997) Multiple testing of general contrasts using logical constraints and correlations. J Am Stat Assoc 92, 299-306

[24] Syed GM, Eagger S, Toone BK, Levy R, Barrett JJ (1992) Quantification of regional cerebral blood flow (rCBF) using ${ }^{9}$ 9Tcm-HMPAO and SPECT: Choice of the reference region. Nucl Me Commun 13, 811-816.

[25] Nishimura T, Hashikawa K, Fukuyama H, Kubota T, Kitamura S, Matsuda H, Hanyu H, Nabatame H, Oku N, Tanabe H, Kuwabara Y, Jinnouchi S, Kubo A (2007) Decreased cerebral blood flow and prognosis of Alzheimer's disease: A multicenter HMPAO-SPECT study. Ann Nucl Med 21, 15-23.

[26] May JM, Qu Z-c, Cobb CE (2004) Reduction and uptake of methylene blue by human erythrocytes. Am J Physiol Cell Physiol 286, C1390-C1398.

[27] Murthy ASN, Reddy KS (1984) Cyclic-voltammetric studies of some phenothiazine dyes. J Chem Soc Faraday Trans 1 Phys Chem Condensed Phases 80, 2745-2750.

[28] Green RC, Schneider LS, Hendrix SB, Zavitz KH, Swabb E (2008) O3-04-01: Safety and efficacy of tarenflurbil in subjects with mild Alzheimer's disease: Results from an 18month multi-center phase 3 trial. Alzheimers Dement 4, T165.

[29] Salloway S, Sperling R, Fox NC, Blennow K, Klunk W, Raskind M, Sabbagh M, Honig LS, Porsteinsson AP, Ferris S, Reichert M, Ketter N, Nejadnik B, Guenzler V, Miloslavsky M, Wang D, Lu Y, Lull J, Tudor IC, Liu E, Grundman M,
Yuen E, Black R, Brashear HR (2014) Two phase 3 trials of bapineuzumab in mild-to-moderate Alzheimer's disease. $N$ Engl J Med 370, 322-333.

[30] Doody RS, Thomas RG, Farlow M, Iwatsubo T, Vellas B, Joffe S, Kieburtz K, Raman R, Sun X, Aisen PS, Siemers E, Liu-Seifert H, Mohs R (2014) Phase 3 trials of solanezumab for mild-to-moderate Alzheimer's disease. N Engl J Med 370, 311-321.

[31] Gold M (2007) Study design factors and patient demographics and their effect on the decline of placebo-treated subjects in randomized clinical trials in Alzheimer's disease. J Clin Psychiatry 68, 430-438.

[32] Aisen PS, Schneider LS, Sano M, Diaz-Arrastia R, van Dyck CH, Weiner MF, Bottiglieri T, Jin S, Stokes KT, Thomas RG, Thal LJ, for the Alzheimer Disease Cooperative, Study (2008) High-dose B vitamin supplementation and cognitive decline in Alzheimer disease: A randomized controlled trial. J Am Med Assoc 300, 1774-1783.

[33] Wilcock GK, Black SE, Hendrix SB, Zavitz KH, Swabb EA, Laughlin MA (2008) Efficacy and safety of tarenflurbil in mild to moderate Alzheimer's disease: A randomised phase II trial. Lancet Neurol 7, 483-493.

[34] Aisen PS, Schafer KA, Grundman M, Pfeiffer E, Sano M, Davis KL, Farlow MR, Jin S, Thomas RG, Thal LJ, for the Alzheimer's Disease Cooperative, Study (2003) Effects of rofecoxib or naproxen vs placebo on Alzheimer disease progression: A randomized controlled trial. JAMA $\mathbf{2 8 9}$, 2819-2826.

[35] Sano M, Ernesto C, Thomas RG, Klauber MR, Schafer K, Grundman M, Woodbury P, Growdon J, Cotman CW, Pfeiffer E, Schneider LS, Thal LJ, The Members of the Alzheimer's Disease Cooperative, Study (1997) A controlled trial of selegiline, alpha-tocopherol, or both as treatment for Alzheimer's disease. N Engl J Med 336, 1216-1222.

[36] Bradley KM, O’Sullivan VT, Soper NDW, Nagy Z, King EM-F, Smith AD, Shepstone BJ (2002) Cerebral perfusion SPET correlated with Braak pathological stage in Alzheimer's disease. Brain 125, 1772-1781.

[37] Matsuda H (2007) Role of neuroimaging in Alzheimer's disease, with emphasis on brain perfusion SPECT. J Nucl Med 48, 1289-1300.

[38] Herholz K, Schopphoff H, Schmidt M, Mielke R, Eschner W, Scheidhauer K, Schicha H, Heiss W-D, Ebmeier K (2002) Direct comparison of spatially normalized PET and SPECT scans in Alzheimer's disease. J Nucl Med 43, 21-26.

[39] Mukaetova-Ladinska EB, Garcia-Sierra F, Hurt J, Gertz HJ, Xuereb JH, Hills R, Brayne C, Huppert FA, Paykel ES, McGee M, Jakes R, Honer WG, Harrington CR, Wischik CM (2000) Staging of cytoskeletal and $\beta$-amyloid changes in human isocortex reveals biphasic synaptic protein response during progression of Alzheimer's disease. Am J Pathol 157, 623-636. 